\title{
O CONHECIMENTO DOS ESTUDANTES DE CIÊNCIAS CONTÁBEIS ACERCA DO CÓDIGO DE ÉTICA
}

\section{The knowledge of Accounting students regarding the Code of Ethics}

\begin{abstract}
Karina Silveira da Cunha
E-mail: karina_lagoa@hotmail.com

Bacharel em Ciências Contábeis pela Universidade Federal de Santa Catarina; Gerente de

Auditoria na Empresa Matos Auditores Independentes.

https://orcid.org/0000-0002-7603-2530

Maria Denize Henrique Casagrande

E-mail: denize_casagrande@yahoo.com.br

Doutora em Engenharia de Produção pela Universidade Federal de Santa Catarina; Mestra em Engenharia de Produção pela Universidade Federal de Santa Catarina; Professora no Departamento de Ciências Contábeis da Universidade Federal de Santa Catarina. https://orcid.org/0000-0003-4137-1679
\end{abstract}

Sandro Vieira Soares

E-mail: sandrovieirasoares@hotmail.com

Doutor em Controladoria e Contabilidade pela Faculdade de Economia, Administração,

Contabilidade e Atuária da Universidade de São Paulo; Pós-doutor em Administração pela Universidade do Sul de Santa Catarina; Professor no Programa de Pós-graduação em Administração da Universidade do Sul de Santa Catarina. Endereço para contato: Rua Antônio Dib Mussi, 366, Centro, 88015-110, Florianópolis, Santa Catarina, Brasil. https://orcid.org/0000-0001-7076-4936

Alan Diógenes Góis E-mail: alandgois@hotmail.com

Doutor em Controladoria e Contabilidade pela Faculdade de Economia, Administração, Contabilidade e Atuária da Universidade de São Paulo; Pós-doutorando em Administração de Empresas na Escola de Administração de Empresas de São Paulo da Fundação Getúlio Vargas; Professor no Mestrado Profissional em Controladoria e Finanças da Faculdade FIPECAFI. https://orcid.org/0000-0003-3534-6557

Artigo recebido em 2 de julho de 2019. Aceito em 17 de agosto de 2020. 


\section{Resumo}

O Código de Ética Profissional do Contador (CEPC) objetiva fixar a forma pela qual os contadores devem seguir no exercício da profissão e com relação à classe, e o conhecimento de seu teor é um dos componentes do Exame de Suficiência do Conselho Federal de Contabilidade. Esta pesquisa teve por objetivo principal verificar qual o nível de conhecimento dos estudantes do Curso de Ciências Contábeis da Universidade Federal de Santa Catarina, acerca do CEPC. A pesquisa quantitativa foi realizada por meio de um levantamento que se baseou em questões presentes nos Exames de Suficiência do Conselho Federal de Contabilidade. Participaram da pesquisa 101 estudantes matriculados na $2^{a}$ e na $4^{a}$ fases do Curso. Os resultados apontaram que a média de acertos de alunos que já cursaram a disciplina (Ética e Filosofia Política) é, estatisticamente, maior que de alunos que ainda não cursaram a disciplina. A mediana do número de acertos de alunos que já cursaram a disciplina é o dobro dos indicados por alunos que ainda não cursaram. Tais resultados sustentam a conclusão de que cursar a disciplina impacta, positivamente, o desempenho das questões sobre ética. No entanto, a análise do desempenho dos dois grupos, por questão, revelou que a proporção de acertos dos alunos que já cursaram a disciplina é, estatisticamente, maior dos que não cursaram em apenas 5 das 18 questões analisadas. Tais resultados, à luz do teor das questões em que houve melhora do desempenho, sustentam a conclusão que cursar a disciplina impacta, positivamente, o desempenho em um número restrito e pequeno de questões.

Palavras-chave: Código de Ética Profissional do Contador. Ética Profissional. Contabilidade.

\section{Abstract}

The Accountant's Professional Code of Ethics (CEPC) aims to set the way which accountants must follow in the exercise of their profession and with regards to their professional class, and knowledge of its contents is one of the components of the Sufficiency Exam of the Federal Accounting Council. This research aims to verify the level of knowledge that the students of the Accounting Sciences Course in the Federal University of Santa Catarina have with regards to the CEPC. The qualitative research was done via a survey based on questions from the Sufficiency Exam of the Federal Accounting Council. The research had the participation of 101 students enrolled in the 2nd and 4th stages of the Course. The results show that the average number of correct answers for students who took the class (Ethics and Political Philosophy) is statistically higher than that of students who did not take the class. The median of that count for the students who took the class is twice that of the students who did not take the class. These results support the conclusion that taking the class positively impacts the students' performance on ethics-related questions. However, the analysis, per question, of the performance of both groups revealed that the proportion of correct answers for the students who already took the class is statistically higher than that of the students who did not take the class yet in only 5 of the 18 questions analyzed. These results, considering the content of the questions in which there was an increase in performance, support the conclusion that taking the class positively impacts the students' performance in a restricted and small number of questions.

Keywords: Accountant's Professional Code of Ethics. Professional Ethics. Accounting. 


\section{INTRODUÇÃO}

Nos últimos anos, um dos assuntos mais comentados nos meios de comunicação tem sido a fraude e a corrupção, em razão de diversos escândalos que aconteceram ao redor do mundo (Liu, 2016; Soltani, 2014; Timmons \& Garfias, 2015). As consequências desses escândalos criaram um profundo mal-estar corporativo e uma economia de mercado de capital desconfiada, em que a recente crise financeira representa a maior manifestação de muitos desses fatores disruptivos que afetam o bom funcionamento do mercado financeiro (Soltani, 2014). Ademais, tanto a fraude quanto a corrupção estão presentes em todos os níveis da sociedade, criando empecilhos no desenvolvimento da economia.

Esses escândalos surgem pela falta de melhores práticas de governança, controles internos e códigos de conduta ética para todos os níveis da empresa (Neu, Everett, \& Rahaman, 2015). Entre esses, o Código de Ética vem ganhando atenção tanto na literatura nacional quanto na literatura internacional, uma vez que tem como objetivo impactar a tomada de decisão individual e, assim, prevenir atitudes oportunistas (Chen, Gotti, Kang, \& Wolfe, 2018).

Além do Código de Ética adotado pelas empresas, muitos profissionais liberais estão sujeitos a códigos de ética profissional (Merchant \& White, 2017). Esses padrões são desenvolvidos por órgãos de licenciamento, reguladores e organizações profissionais, expressando prescrições comportamentais e virtudes, os quais são revisados, conforme a necessidade de comitês de ética ou compliance (Merchant \& White, 2017). Esses códigos de ética profissional definem penalidades que podem ser tão severas como a suspensão ou perda da licença profissional (Merchant \& White, 2017).

Entre os profissionais liberais, os contadores são aqueles que, frequentemente, sofrem influência por parte da gestão e vivenciam dilemas éticos (Almeida \& Alves, 2015), entre os quais a pressão é um dos fatores para o surgimento de fraude (Cressey \& Moore, 1983). Diante desse cenário, o Conselho Federal de Contabilidade, por meio da Resolução CFC 803, aprovou o Código de Ética Profissional do Contador (CEPC), que "tem por objetivo fixar a forma pela qual se devem conduzir os Profissionais da Contabilidade, quando no exercício profissional e nos assuntos relacionados à profissão e à classe" (Conselho Federal de Contabilidade [CFC], 1996).

Por ser relevante para a conduta profissional e por ser tema relevante no ambiente corporativo, a ética geral e profissional se faz presente nos currículos dos Cursos de Ciências Contábeis em faculdades e universidades. Essa disciplina objetiva informar sobre princípios éticos fundamentais, responsabilidade social e individual e infrações ao Código de Ética Profissional do Contabilista e à ética dos negócios (Lisboa, 2010). Além disso, o conteúdo 
dessa disciplina está presente no Exame de Suficiência, por meio do qual o Bacharel em Contabilidade aprovado poderá exercer a profissão Contábil.

Portanto, percebe-se que há um apelo da sociedade e do meio corporativo para o desenvolvimento de atributos inibidores de ações oportunistas e para a criação de habilidades voltadas à integridade e ética, com o intuito de reduzir fraudes e corrupção. Assim, é relevante analisar como os alunos de Ciências Contábeis, os futuros contadores, estão absorvendo o conhecimento sobre ética geral e profissional.

Diante disso, a presente pesquisa tem por objetivo verificar o nível de conhecimento dos estudantes do Curso de Ciências Contábeis de uma universidade federal acerca do Código de Ética Profissional do Contador (CEPC). Dessa maneira, a pesquisa baseou-se em questões presentes nos Exames de Suficiência do Conselho Federal de Contabilidade, ajustadas de acordo com a necessidade de enquadramento no questionário.

$\mathrm{Na}$ continuidade, organiza-se o artigo, inicialmente, elencando aspectos teóricos e conceituais sobre ética profissional, o Código de Ética Profissional do Contador e sua importância. Na sequência, discorre-se sobre a disciplina que aborda a temática Ética no Curso, discutindo-se, posteriormente, os estudos relevantes sobre Ética na Contabilidade. Por fim, apresentam-se a análise de dados e as conclusões sobre a pesquisa.

\section{REVISÃO DA LITERATURA}

Esta seção está dividida em subseções que tratam do Código de Ética Profissional do Contador e de estudos anteriores sobre Ética na Contabilidade.

\subsection{CÓDIGO DE ÉTICA PROFISSIONAL DO CONTADOR (CEPC)}

Entre as diversas profissões, o Contador é aquele que dispõe de um dos maiores mercados de trabalho (Sá, 2010), pois as empresas necessitam de sua assessoria contínua $e$, com isso, a responsabilidade é equivalente aos seus deveres, seu reconhecimento e às recompensas da profissão.

O profissional da Contabilidade se depara com inúmeros dilemas éticos no decorrer de sua profissão. Esses dilemas estão ligados, em um todo, entre: dever, direito, justiça, responsabilidade, consciência e vocação. Com isso, o autor ainda coloca o Código de Ética como uma enumeração de práticas éticas comportamentais, que, espera-se, sejam verificadas na profissão (Lisboa, 2010).

Ainda de acordo com Lisboa (2010, p. 88), as normas do Código de Ética "visam o bem-estar da sociedade, de forma a assegurar a lisura de procedimentos dos seus membros 
dentro e fora da instituição" (p. 88). Então, o Código de Ética Profissional é a construção da percepção profissional sobre práticas de conduta.

Inicialmente, Camargo (2009, p. 33) diz que os Códigos de Ética Profissional "[...] estruturam e sistematizam as exigências éticas no tríplice plano de orientação, disciplina e fiscalização". Secundariamente, eles estabelecem fundamentos variáveis e relativos que restringem fronteiras, das quais a conduta pode ou deve ser julgada aceitável do ponto de vista ético. Camargo (2009) alerta que, em algumas circunstâncias particulares, os códigos nem sempre apontam a maneira mais apropriada de se proceder.

Após 26 anos de vigência da Resolução CFC 290 de 1970, a fim de aprimorar o Código de Ética Profissional do Contabilista, surge a Resolução CFC 803 (CFC, 1996), aprovando o Código de Ética Profissional do Contador (CEPC), com o objetivo de atualizar os conceitos éticos na área da atividade contábil. O CEPC está dividido em seis capítulos: objetivo; dos deveres e das proibições; valor dos serviços profissionais; deveres com relação aos colegas e à classe; penalidades; e disposições gerais.

O primeiro capítulo traz o objetivo do Código, que é fixar a forma na qual os profissionais da Contabilidade devem se comportar diante do exercício da profissão e nos assuntos da classe. Estão dispostos no segundo capítulo os deveres dos profissionais, bem como as suas penalidades. Entre os deveres, existem os que versam sobre: exercer a profissão com zelo; guardar sigilo; renunciar a função, quando tiver falta de confiança por terceiros; e cumprir os programas obrigatórios de educação continuada, estabelecidos pelo CFC. Quando o Contador for perito, assistente técnico, auditor ou árbitro deve recusar trabalho por não se achar capacitado para tal, e ser imparcial nos laudos submetidos a ele.

Com relação às proibições, algumas que merecem destaque são: assinar documentos ou demonstrações elaborados por outros, longe da sua supervisão, orientação e fiscalização; ter organização contábil fora da legislação vigente; possuir agenciador de negócios, em que este terá participação nos seus honorários; reter livros, papéis e documentos que a ele foram confiados; revelar negociações; iludir ou tentar iludir a boa-fé do cliente; e fazer menção de título profissional que não possua.

O terceiro capítulo dispõe sobre os honorários da classe, que devem ser prefixados no contrato de acordo com vários itens, como o local do serviço, se o cliente é eventual, habitual ou permanente, entre outros. No quarto capítulo, estão presentes os deveres quanto aos colegas e à classe. A relação com os colegas deve ser de consideração, respeito, apreço e solidariedade, o que não justifica a participação ou convivência com um erro. No que diz respeito à classe, um dos principais regramentos é zelar pelo cumprimento do Código. As penalidades aplicadas pelo não cumprimento do disposto no Código estão presentes no quinto capítulo, bem como alguns itens que podem ser agravantes ou atenuantes da pena. 


\subsection{ESTUDOS ANTERIORES SOBRE ÉTICA NA CONTABILIDADE}

A pesquisa sobre a ética e os estudantes de Contabilidade no Brasil é pouco numerosa (Bueno, 2017; Monteiro, Silva, Peter, \& Machado, 2011). Monteiro et al. (2011) encontraram apenas seis artigos sobre Ética e Contabilidade, entre os 7.756 artigos publicados pelo Enanpad na década de 2000, enquanto Bueno (2017) encontrou apenas 10 artigos sobre o tema, publicados em periódicos brasileiros, e 118 no âmbito internacional.

Por outro lado, em pesquisa bibliográfica realizada para o presente artigo, um número de mais de 40 pesquisas foi encontrado em busca realizada em agosto de 2018, nas revistas e anais de eventos em Administração e Contabilidade brasileiros. As pesquisas encontradas, que tratam da Ética segundo estudantes de Contabilidade, datam sua publicação, principalmente, a partir de 2010: Brancher, Neu, e Boff (2010), Campos e Lima (2013), Diehl, Freitas, e Macagnan (2011), Feil, Diehl, e Schuck (2017), Ferreira e Souza (2014), Lima, Prazeres, Araújo, e Araújo (2014), Mafra, Teixeira, Silva, Costa, e Costa (2007), Medeiros e Vieira (2010), Moraes, Silva, e Carvalho (2010), Nascimento, Bezerra, Espejo, Pacheco, e Antonovz (2010), Nunes, Leite, e Souza (2010), Oliveira, Jesus, Silva, Silva, e Nascimento (2014), Rocha, Oliveira, Borges, e Sanchez (2015), Silva (2014), Silva, Oliveira, Ramos, e Soares (2010) e Trentin, Domingues, e Castro (2008).

A maioria das pesquisas (Diehl et al., 2011; Feil et al., 2017) que investigou o conhecimento ou a percepção de estudantes de Contabilidade sobre Ética ou CEPC se utilizaram de levantamento em uma única instituição de ensino escolhida por acessibilidade, com exceções em que o survey foi realizado em duas (Moraes et al., 2010) ou quatro IES (Nascimento et al., 2010). Os surveys realizados envolviam alunos de todas as fases do Curso, alunos ingressantes e concluintes, alunos apenas concluintes e alunos da segunda metade do Curso, mas nenhuma pesquisa foi aplicada imediatamente antes e depois de o aluno cursar a disciplina de Ética, como a presente pesquisa o fez.

A maioria das questões utilizadas para mensurar o conhecimento e a percepção sobre ética eram subjetivas e declaratórias (Brancher et al., 2010; Ferreira \& Souza, 2014; Lima et al., 2014; Medeiros \& Vieira, 2010; Moraes et al., 2010; Nascimento et al., 2010; Nunes et al., 2010; Oliveira et al., 2014; Rocha et al., 2015; Silva et al., 2010; Trentin et al., 2008). Uma minoria de questões era baseada no CEPC e verificou, de fato, se a resposta estava de acordo com o CEPC ou não (Campos \& Lima, 2013; Diehl et al., 2011; Feil et al., 2017; Mafra et al., 2007; Silva, 2014). Também foram minoria as pesquisas que mostravam o questionário aplicado como apêndice ou que as questões pudessem ser identificadas dentro do trabalho (Moraes et al., 2010; Nascimento et al., 2010). Por outro lado, duas pesquisas (Feil et al., 2017; Silva, 2014) replicaram o questionário de Diehl et al. (2011). 
Das pesquisas em que se podia identificar se havia diferença do conhecimento de Ética dos estudantes de Contabilidade antes e depois de fazerem a disciplina de Ética, os resultados foram controversos: enquanto Trentin et al. (2008) identificaram que alunos acertaram mais questões depois de cursar a disciplina de Ética, Brancher et al. (2010) afirmaram que houve pouca diferença, Ferreira e Souza (2014), Mafra et al. (2007) e Medeiros e Vieira (2010) afirmaram que não houve diferença. Segundo as pesquisas consultadas (Oliveira et al., 2014; Trentin et al., 2008), a disciplina de Ética é ministrada entre a terceira e a última fases do Curso.

Entre as 10 pesquisas que investigaram se alunos conheciam/leram o CEPC, Campos e Lima (2013), Diehl et al. (2011), Medeiros e Vieira (2010), Nunes et al. (2010), Silva (2014) e Trentin et al. (2008) constataram que mais da metade dos respondentes desconheciam ou nunca leram o CEPC. Ainda assim, oito pesquisas apontaram que os respondentes julgavam - CEPC necessário ou importante, e a Ética importante para o exercício profissional (Campos \& Lima, 2013; Diehl et al., 2011; Ferreira \& Souza, 2014; Lima et al., 2014; Nascimento et al., 2010; Nunes et al., 2010; Oliveira et al., 2014; Silva et al., 2010).

\section{MÉTODO DE PESQUISA}

A presente pesquisa trata de um levantamento (survey), com abordagem de dados qualiquantitativa, com coleta de dados feita por meio de questionário. $O$ processo para a definição da amostra da população do estudo foi a amostragem por conveniência (Cooper \& Schindler, 2016; Gil, 2016; Malhotra, 2019; Sampieri, Collado, \& Lucio, 2013). O levantamento (survey) é a estratégia de pesquisa mais utilizada em pesquisas brasileiras e internacionais sobre Ética (Bueno, 2017).

A coleta de dados ocorreu por meio de um questionário com perguntas objetivas, divididas em duas partes: a primeira parte com oito questões para identificar o perfil do entrevistado, verificar se a ele já foi apresentado o CEPC e se já cursou a disciplina de Ética e Filosofia Política (FIL5109); a segunda parte do questionário, com mais 18 questões, baseadas no conteúdo do CEPC e adaptadas das questões do Exame de Suficiência do Conselho Federal de Contabilidade, desde a sua primeira edição, em 2011, até a segunda edição de 2016, foi desenvolvida para identificar o conhecimento dos estudantes sobre os diversos temas constantes no CEPC.

As questões utilizadas, retiradas das provas do Exame de Suficiência, estão indicadas na Tabela 1: 
Tabela 1

Questões do Exame de Suficiência utilizadas no questionário

\begin{tabular}{lcc}
\multicolumn{1}{c}{ Prova } & Questões do Exame & Questionário \\
\hline $1^{\circ}$ Exame de Suficiência de 2011 & 38 e 39 & Q9, Q10 e Q11 \\
$2^{\circ}$ Exame de Suficiência de 2011 & 42 e 43 & Q12 e Q13 \\
$1^{\circ}$ Exame de Suficiência de 2012 & 42,43 e 44 & Q14, Q15 e Q16 \\
$2^{\circ}$ Exame de Suficiência de 2012 & 37 & Q17 \\
$1^{\circ}$ Exame de Suficiência de 2013 & 44 & Q18 \\
$2^{\circ}$ Exame de Suficiência de 2013 & 46 e 47 & Q20 e Q21 \\
$1^{\circ}$ Exame de Suficiência de 2014 & 36 & Q22 \\
$2^{\circ}$ Exame de Suficiência de 2014 & Nenhuma \\
$1^{\circ}$ Exame de Suficiência de 2015 & 40 & Q23 \\
$2^{\circ}$ Exame de Suficiência de 2015 & 40 & Q24 \\
$1^{\circ}$ Exame de Suficiência de 2016 & 42 & Q25 \\
$2^{\circ}$ Exame de Suficiência de 2016 & 46 & Q26
\end{tabular}

As questões do Exame de Suficiência foram adaptadas para que, no questionário, todas tivessem a mesma estrutura, como no exemplo a seguir, que trata da adaptação da questão 39 da primeira prova de 2011:

39. Com relação ao comportamento dos profissionais da Contabilidade, analise as situações hipotéticas apresentadas nos itens abaixo e, em seguida, assinale a opção CORRETA:

I. Um contabilista iniciante contratou um agenciador de serviços para atuar na captação de clientes. Para cada cliente captado, o agenciador irá receber $1 \%$ dos honorários acertados.

II. Em razão de sua aposentadoria, o Contabilista transferiu seus contratos de serviço para seu genro, também Contabilista. Os clientes foram contatados um a um, por telefone, e se manifestaram de acordo com a mudança.

III. Um perito-contador, indicado pelo juiz para atuar em uma questão relativa a uma dissolução de sociedade, recusou-se a assumir o trabalho por não se achar capacitado. De acordo com as três situações acima descritas, o comportamento do profissional da Contabilidade está em DESACORDO com os deveres descritos no Código de Ética Profissional do Contabilista nos itens:

a) I, II e III.

b) I e II, apenas.

c) I, apenas.

d) II e III, apenas. (CFC, 2011, p. 21). 
Essa questão foi adaptada para ser as questões Q10 e Qll do questionário, com a seguinte forma:

10. Um Contabilista iniciante contratou um agenciador de serviços para atuar na captação de clientes. Para cada cliente captado, o agenciador irá receber $1 \%$ dos honorários acertados. Essa atitude está de acordo com o CEPC?

( ) Sim

( ) Não

( ) Não sei

11. Um perito-contador, indicado pelo juiz para atuar em uma questão relativa a uma dissolução de sociedade, recusou-se a assumir o trabalho por não se achar capacitado. Essa atitude está de acordo com o CEPC?

( ) Sim

( ) Não

( ) Não sei

A adaptação aumentou a probabilidade de acerto em escolha aleatória de $25 \%$ do Exame de Suficiência para 50\% para o questionário da presente pesquisa.

Antes da aplicação do questionário com a amostra final, foi realizado um pré-teste com uma turma de 22 alunos. A amostra, composta por todos os estudantes do Curso de Ciências Contábeis da Universidade Federal pesquisada, que cursaram a segunda e a quarta fases dos períodos matutino e noturno, contou com 101 questionários, respondidos durante - mês de maio de 2017, representando o semestre 2017/1, em que estavam matriculados 163 alunos: 103 na segunda fase e 60 na quarta fase. Assim, a amostra final foi composta por 101 respondentes: 62 da segunda fase e 39 respondentes da quarta fase.

A coleta de dados foi feita, pessoalmente, por uma das autoras do presente artigo. No início da aula, após contato prévio e autorização do professor que estava em sala, a pesquisadora se apresentou e apresentou a finalidade da pesquisa e o tema. Depois disso, explicou as questões do primeiro bloco e do segundo bloco, informando que, neste, tratavam-se de questões adaptadas do Exame de Suficiência, e que o objetivo era verificar o conhecimento dos alunos sobre o tema; caso não soubessem a resposta, poderiam assinalar "Não sei". Todos os alunos presentes em sala concordaram em participar, de modo que não foi recebido nenhum questionário em branco. Os professores disponibilizaram 30 minutos para a aplicação do questionário, mas a maioria dos alunos entregou em menos tempo; 
poucos alunos usaram os 30 minutos. Na terceira fase do Curso é ministrada a disciplina de Ética e Filosofia Política, por isso, foi feita a verificação sobre o desempenho dos alunos antes e depois da disciplina, isto é, na segunda e na quarta fases. Para a apuração dos resultados foram utilizadas técnicas de estatística descritiva, testes de diferença de média e proporção, e uma breve análise do conteúdo das questões. Com isso, permitiu-se fazer a interpretação dos dados para responder ao problema abordado pela pesquisa.

\section{ANÁLISE DOS RESULTADOS}

Esta seção está dividida em duas subseções, em que, na primeira parte, apresenta-se a caracterização dos respondentes; e, na segunda parte, faz-se a análise dos dados.

\subsection{CARACTERIZAÇÃO DOS RESPONDENTES}

De posse dos questionários respondidos, inicialmente, fez-se a tabulação em uma planilha eletrônica Microsoft Excel. Nesta subseção, faz-se a caracterização dos respondentes, a partir dos dados obtidos por meio das oito questões iniciais do questionário, que pretendiam traçar o perfil dos respondentes. As questões dicotômicas são apresentadas em conjunto na Tabela 2, enumeradas conforme o questionário aplicado aos respondentes.

Tabela 2

Caracterização dos respondentes por fase, segundo as perguntas dicotômicas

\begin{tabular}{|c|c|c|c|c|c|}
\hline \multirow{2}{*}{$\frac{\text { Questão }}{1 \text { Você está cursando predominantemente qual fase? }}$} & \multicolumn{2}{|c|}{ Segunda fase } & \multicolumn{2}{|c|}{ Quarta fase } & \multirow{2}{*}{$\begin{array}{r}\text { Total } \\
101\end{array}$} \\
\hline & & 62 & & 39 & \\
\hline \multirow{2}{*}{2 Você já exerce atividade remunerada em Contabilidade? } & Sim & Não & Sim & Não & Total \\
\hline & 20 & 42 & 28 & 11 & 101 \\
\hline \multirow{2}{*}{3 Você já cursou a disciplina de Ética e Filosofia Política (FIL5109)? } & Sim & Não & Sim & Não & Total \\
\hline & 0 & 62 & 39 & 0 & 101 \\
\hline \multirow{2}{*}{$\begin{array}{l}4 \text { Você conhece o Código de Ética Profissional do Contador (CEPC) } \\
\text { criado pela Resolução CFC } 803 \text { (CFC, 1996)? }\end{array}$} & Sim & Não & Sim & Não & Total \\
\hline & 6 & 56 & 8 & 31 & 101 \\
\hline \multirow{2}{*}{$\begin{array}{l}7 \text { Você acha importante o Código de Ética Profissional do Contador } \\
\text { (CEPC)? }\end{array}$} & Sim & Não & Sim & Não & Total \\
\hline & 62 & 0 & 37 & 2 & 101 \\
\hline \multirow{2}{*}{$\begin{array}{l}8 \text { Você acha importante a existência de Códigos de Ética para avo- } \\
\text { gados, administradores e economistas? }\end{array}$} & Sim & Não & Sim & Não & Total \\
\hline & 62 & 0 & 36 & 3 & 101 \\
\hline
\end{tabular}


A Questão Q3 foi uma questão de controle, colocada no questionário para garantir que o aluno, mesmo cursando predominantemente a segunda e a quarta fases do Curso, não tivesse cursado e estivesse cursando, respectivamente, a disciplina, já que, tendo em vista o objetivo da pesquisa, era importante separar quem já tinha cursado a disciplina de quem ainda não a tinha cursado. A Tabela 2 indica, ainda, que os respondentes, em sua maioria, acreditam na importância dos códigos de ética profissionais.

A Tabela 3 apresenta o resultado das duas únicas questões de múltipla escolha do primeiro bloco do questionário.

Tabela 3

Caracterização dos respondentes por fase, segundo as perguntas de múltipla escolha

\begin{tabular}{|c|c|c|}
\hline 5 Se respondeu SIM na questão 3, onde o CEPC lhe foi apresentado? & Segunda fase & Quarta fase \\
\hline Disciplina de Ética e Filosofia Política & 0 & 5 \\
\hline Evento acadêmico universitário & 0 & 0 \\
\hline CRC & 2 & 0 \\
\hline Outra disciplina do Curso & 4 & 1 \\
\hline Internet & 0 & 2 \\
\hline Outro. Qual? & 0 & 0 \\
\hline Total & 6 & 8 \\
\hline $\begin{array}{l}6 \text { Em qual fase você acha que deveria ser ministrada uma disciplina que } \\
\text { abordasse a Ética }\end{array}$ & Segunda fase & Quarta fase \\
\hline $1^{a}$ fase & 16 & 13 \\
\hline $2^{a}$ fase & 9 & 6 \\
\hline $3^{a}$ fase & 18 & 8 \\
\hline $4^{a}$ fase & 5 & 3 \\
\hline $5^{a}$ fase & 4 & 1 \\
\hline $6^{a}$ fase & 2 & 2 \\
\hline $7^{a}$ fase & 1 & 2 \\
\hline $8^{a}$ fase & 7 & 4 \\
\hline Total & 62 & 39 \\
\hline
\end{tabular}

A Tabela 3 permite visualizar que muitos respondentes deixaram de responder à questão Q5 do questionário, e, como este foi aplicado impresso, não é possível obrigar o preenchimento da questão, como quando se usam aplicativos como o Google Forms, por exemplo. Além disso, nem todos os alunos responderam "Sim" à questão Q3. Já a Questão Q6 foi respondida por todos e evidenciou uma concentração maior de respostas entre a 
primeira e a terceira fases do Curso, indicando que os alunos acreditam que o início deste é o melhor momento para a oferta da disciplina.

Na próxima subseção, discute-se o segundo bloco do questionário.

\subsection{ANÁLISE DOS DADOS}

Nesta seção, faz-se a análise das respostas da segunda parte do questionário. A primeira análise desenvolvida foi acerca da estatística descritiva (Tabela 4) dos acertos das duas turmas, a qual foi feita com a ferramenta de Análise de dados do Microsoft Excel.

Tabela 4

Estatística descritiva do desempenho das turmas

\begin{tabular}{lrr}
\hline & Estatística & Quarta fase \\
\hline Média & 2,70 & 4,15 \\
Erro padrão & 0,26 & 0,30 \\
Mediana & 2,22 & 4,44 \\
Moda & 0,00 & 3,33 \\
Desvio padrão & 2,07 & 1,85 \\
Variância da amostra & 4,28 & 3,43 \\
Curtose & $-0,75$ & 0,29 \\
Assimetria & 0,36 & $-0,06$ \\
Intervalo & 7,22 & 8,33 \\
Mínimo & 0,00 & 0,00 \\
Máximo & 7,22 & 8,33 \\
Soma & 167,22 & 161,67 \\
Contagem & 62 & 39 \\
\hline
\end{tabular}

Como se pode ver na Tabela 4, a média dos acertos das questões sobre ética é maior entre os alunos que já cursaram a disciplina $(4,15)$, em valores absolutos, do que entre aqueles que ainda não cursaram $(2,70)$. A mediana dos alunos que já cursaram a disciplina $(4,44)$ é o dobro da mediana dos alunos que ainda não cursaram $(2,22)$. Esses resultados vão ao encontro do que era esperado pelos autores, em consonância com os achados de Trentin et al. (2008), ou seja, alunos que cursam a disciplina de Ética e Filosofia Política acertam mais questões do que os que não cursaram. Observa-se, ainda, que esses resultados se constataram em alunos de uma universidade pública, em que os resultados no Exame de Suficiência são maiores do que nas instituições privadas e nos centros universitários e faculdades (Marçal, Matos, Carvalho, \& Carvalho, 2019). 
No entanto, apesar de a média dos alunos que já cursaram a disciplina ser, matematicamente, maior que dos alunos que ainda não cursaram, procedeu-se a um teste estatístico de diferenças de médias. Inicialmente, testou-se se as distribuições de frequência das notas seguiam a distribuição normal, usando o teste Shapiro-Francia (grupo $1: z=$ $-1,864$; sig. = 0,968 e grupo $2: z=-1,133$; sig. = 0,871). Então, como a estatística $z$ é maior que $5 \%$, pode-se afirmar que a amostra tem normalidade. Após a identificação de que as distribuições de notas dos dois grupos de alunos é normal, procedeu-se ao teste de Levene de igualdade de variâncias. Como o nível de significância desse teste $(F=1,646$; sig. $=0,202)$ foi superior a 0,05, pôde-se concluir que as variâncias são homogêneas.

Considerando que os pressupostos da normalidade dos dados e da homogeneidade de variância foram atendidos, procedeu-se ao teste $t$ de diferenças de médias das notas entre os grupos de alunos que cursaram ou não a disciplina de Ética e Filosofia Política. Os resultados do teste $t(t=-3.565 ; \mathrm{gl}=99$; sig. $=0,001)$ permitem rejeitar, a um nível de significância de 0,05, a hipótese nula de que as médias sejam iguais. Logo, esse resultado contradiz os estudos de Ferreira e Souza (2014), Mafra et al. (2007) e Medeiros e Vieira (2010), os quais concluíram que cursar a disciplina de Ética não promovia melhoria no nível de acertos de questões relacionadas à Ética.

Diante dos resultados encontrados, optou-se por testar a diferença de proporções de acertos por questão. A Tabela 5 mostra os resultados do teste $z$ de diferença entre proporções:

Tabela 5

Resultados do teste $z$

\begin{tabular}{crrl}
\hline Questão & $z$ & Valor-p & \multicolumn{1}{c}{ Teste bicaudal } \\
\hline 09 & $-1,495$ & 0,135 & Não rejeitar a hipótese nula \\
Q10 & $-1,463$ & 0,143 & Não rejeitar a hipótese nula \\
Q11 & $-2,356^{* *}$ & 0,018 & Rejeitar a hipótese nula \\
Q12 & $-0,870$ & 0,384 & Não rejeitar a hipótese nula \\
Q13 & $-2,848^{* * *}$ & 0,004 & Rejeitar a hipótese nula \\
Q14 & $-2,312^{* *}$ & 0,021 & Rejeitar a hipótese nula \\
Q15 & $-1,007$ & 0,314 & Não rejeitar a hipótese nula \\
Q16 & $-2,229^{* *}$ & 0,026 & Rejeitar a hipótese nula \\
Q17 & $-2,717^{* * *}$ & 0,007 & Rejeitar a hipótese nula \\
Q18 & $-1,330$ & 0,183 & Não rejeitar a hipótese nula \\
Q19 & $-1,735^{*}$ & 0,083 & Não rejeitar a hipótese nula \\
Q20 & $-1,800^{*}$ & 0,072 & Não rejeitar a hipótese nula \\
Q21 & $-0,865$ & 0,387 & Não rejeitar a hipótese nula \\
Q22 & $-1,700^{*}$ & 0,089 Não rejeitar a hipótese nula \\
\hline & &
\end{tabular}




\begin{tabular}{crrr}
\hline Questão & $z$ & Valor-p & Teste bicaudal \\
\hline Q23 & $-1,739^{*}$ & 0,082 & Não rejeitar a hipótese nula \\
Q24 & $-1,674^{*}$ & 0,094 & Não rejeitar a hipótese nula \\
Q25 & $-0,902$ & 0,367 & Não rejeitar a hipótese nula \\
Q26 & $-0,377$ & 0,707 Não rejeitar a hipótese nula \\
\hline Nota. $^{*}$ sig. $<0,1 i^{* *}$ sig. $\left\langle 0,0 ;^{* * *}\right.$ sig. $<0,01$. & &
\end{tabular}

Os resultados do teste indicaram que há diferença estatística na proporção de acertos dos alunos que cursaram ou não a disciplina de Ética e Filosofia Política em apenas duas questões ( 013 e Q17) em um nível de significância de 0,01; e de três questões (Q11, Q14 e Q16) em um nível de significância de 0,05. As questões em que a hipótese nula foi rejeitada em um nível de significância de 0,01 ( 013 e Q17) possuíam os seguintes enunciados:

13. Uma determinada organização contábil presta serviços para diversos clientes. Com o aumento da inadimplência de seus clientes, o Contabilista responsável, ao tomar medidas para garantir o recebimento, passou a reter a documentação das empresas inadimplentes sob condição de recebimento das quantias devidas por elas. Essa atitude está de acordo com o CEPC?

17. Segundo o CEPC, com relação à infração ética, existem três sanções previstas: advertência reservada, censura reservada e censura pública.

Com relação à questão Q13, a proporção de alunos que não cursou a disciplina e respondeu a questão corretamente foi de $25,8 \%$, enquanto a proporção de alunos que cursou a disciplina e acertou a questão foi de $53,8 \%$. Já com relação à questão Q17, a proporção de alunos que não cursou a disciplina e respondeu à questão corretamente foi de $6,5 \%$, enquanto a proporção de alunos que cursou a disciplina e acertou a questão foi de $25,6 \%$.

As respostas a esses itens encontram respaldo no CEPC, nos itens:

Art. $3^{\circ}$ No desempenho de suas funções, é vedado ao Profissional da Contabilidade: .

XII-reter abusivamente livros, papéis ou documentos, comprovadamente confiados à sua guarda; ....

Art. 12 A transgressão de preceito deste Código constitui infração ética, sancionada, segundo a gravidade, com a aplicação de uma das seguintes penalidades:

I-advertência reservada; 


\section{II-censura reservada; \\ III-censura pública. (CFC, 1996).}

Ao se adotar um nível de significância de 0,05, ou seja, menos rigoroso, para o teste $z$ de diferença de proporções, as proporções de respostas corretas, de estudantes que cursaram ou não as disciplinas, das questões Q11, Q14 e Q16, podem ser consideradas, estatisticamente, diferentes. As questões Q11, Q14 e Q16 possuíam os seguintes enunciados:

11. Um perito-contador, indicado pelo juiz para atuar em uma questão relativa a uma dissolução de sociedade, recusou-se a assumir o trabalho por não se achar capacitado. Essa atitude está de acordo com o CEPC?

14. Segundo o CEPC, é vedado ao profissional da Contabilidade iludir ou tentar iludir a boa-fé de cliente, empregador ou de terceiros, alterando ou deturpando o exato teor de documentos, bem como fornecendo falsas informações ou elaborando peças contábeis inidôneas.

16. Segundo o CEPC, são deveres do profissional da Contabilidade cumprir os Programas Obrigatórios de Educação Continuada, estabelecidos pelo Conselho Federal de Contabilidade, e auxiliar a fiscalização do exercício profissional.

As proporções de acertos dessas questões do grupo de alunos que não havia cursado a disciplina e que cursou a disciplina foram, respectivamente, de Q11-25,8\% e 48,7\%, Q14$35,5 \%$ e $59 \%$ e $016-22,6 \%$ e $43,6 \%$. Para responder às questões corretamente, os alunos precisariam conhecer os seguintes itens do CEPC:

Art. $2^{\circ}$ São deveres do Profissional da Contabilidade: ....

$\mathrm{X}$-cumprir os Programas Obrigatórios de Educação Continuada, estabelecidos pelo $\mathrm{CFC}_{i} \ldots .$.

XII-auxiliar a fiscalização do exercício profissional ....

Art. $3^{\circ}$ No desempenho de suas funções, é vedado ao Profissional da Contabilidade: . $\cdots$

XVII-iludir ou tentar iludir a boa-fé de cliente, empregador ou de terceiros, alterando ou deturpando o exato teor de documentos, bem como fornecendo falsas informações ou elaborando peças contábeis inidôneas; .... 
Art. $5^{\circ} \mathrm{O}$ Contador, quando perito, assistente técnico, auditor ou árbitro, deverá:

I-recusar sua indicação quando reconheça não se achar capacitado em face da especialização requerida. (CFC, 1996).

Das três questões antes elencadas, a que mais obteve acertos (014) foi aquela formulada usando termos que transcendem a ética profissional, indo para a ética com o próximo, ao conter a expressão "iludir ou tentar iludir a boa-fé" de algum indivíduo, no caso, o cliente. Já a menos acertada foi a questão Q16, que tem um caráter eminentemente técnico, no âmbito do exercício profissional.

Esses resultados indicam que, com exceção de 5 questões, de um total de 18, a proporção de acertos entre alunos que cursaram ou não a disciplina de Ética foi, estatisticamente, a mesma, disparando o alerta sobre o quanto a disciplina de Ética e Filosofia Política tem contribuído para familiarizar o aluno com o CEPC.

No entanto, essa informação não deve ser tomada de forma isolada. O fato é que, na presente pesquisa, houve a reformulação das questões do Exame de Suficiência, que são questões objetivas de múltipla escolha com quatro alternativas, para um formato de questão cujas respostas de múltipla escolha eram "Sim", "Não" e "Não sei". Assim, a probabilidade de acertos entre os dois formatos de questão é diferente. Ou seja, enquanto no Exame de Suficiência a probabilidade de acerto aleatório ou "chute" é de uma em quatro (25\%), na presente pesquisa os alunos que podiam optar por responder à questão ou assinalar "Não sei, a probabilidade de o aluno acertar a resposta aleatoriamente crescia para um em dois $(50 \%)$.

Dessa forma, a proporção de alunos que responderam errado ou não souberam a resposta da questão acabou mostrando um resultado inesperado, como se pode ver na Tabela 6:

Tabela 6

Proporção de respostas erradas e de "Não sei"

\begin{tabular}{|c|c|c|c|c|c|c|c|c|}
\hline \multirow[b]{2}{*}{ Questão } & \multicolumn{4}{|c|}{ Proporção de respostas erradas } & \multicolumn{4}{|c|}{ Proporção de respostas "Não sei" } \\
\hline & 2 fase & 4 fase & $z$ & $\begin{array}{l}\text { Teste de } \\
\text { hipótese }\end{array}$ & 2 fase & 4 fase & $z$ & $\begin{array}{l}\text { Teste de } \\
\text { hipótese }\end{array}$ \\
\hline Q9 & 0,032 & 0,051 & $-0,477$ & Não rejeitar HO & 0,887 & 0,667 & $2,706^{* * *}$ & Rejeitar HO \\
\hline Q10 & 0,129 & 0,154 & $-0,351$ & Não rejeitar HO & 0,806 & 0,692 & 1,312 & Não rejeitar $\mathrm{HO}$ \\
\hline Q11 & 0,081 & 0,103 & $-0,376$ & Não rejeitar HO & 0,661 & 0,410 & $2,477^{* *}$ & Rejeitar $\mathrm{HO}$ \\
\hline Q12 & 0,210 & 0,410 & $-2,169^{* *}$ & Rejeitar HO & 0,629 & 0,359 & $2,646^{* * *}$ & Rejeitar HO \\
\hline Q13 & 0,032 & 0,077 & $-1,007$ & Não rejeitar HO & 0,710 & 0,385 & $3,227^{* * *}$ & Rejeitar HO \\
\hline Q14 & 0,097 & 0,205 & $-1,534$ & Não rejeitar HO & 0,548 & 0,205 & $3,408^{* * *}$ & Rejeitar HO \\
\hline
\end{tabular}




\begin{tabular}{|c|c|c|c|c|c|c|c|c|}
\hline \multirow[b]{2}{*}{ Questão } & \multicolumn{4}{|c|}{ Proporção de respostas erradas } & \multicolumn{4}{|c|}{ Proporção de respostas "Não sei" } \\
\hline & 2 fase & 4 fase & $\mathbf{z}$ & $\begin{array}{l}\text { Teste de } \\
\text { hipótese }\end{array}$ & 2 fase & 4 fase & $z$ & $\begin{array}{l}\text { Teste de } \\
\text { hipótese }\end{array}$ \\
\hline Q15 & 0,113 & 0,205 & $-1,269$ & Não rejeitar HO & 0,855 & 0,718 & $1,681^{*}$ & Não rejeitar Ho \\
\hline Q16 & 0,032 & 0,179 & $-2,529^{* *}$ & Rejeitar HO & 0,742 & 0,385 & $3,575^{* * *}$ & Rejeitar Ho \\
\hline Q17 & 0,016 & 0,051 & $-1,013$ & Não rejeitar Ho & 0,919 & 0,692 & $2,969^{* * *}$ & Rejeitar Ho \\
\hline Q18 & 0,113 & 0,179 & $-0,943$ & Não rejeitar Ho & 0,758 & 0,590 & $1,786^{*}$ & Não rejeitar Ho \\
\hline Q19 & 0,113 & 0,308 & $-2,439^{* *}$ & Rejeitar Ho & 0,726 & 0,385 & $3,400^{* * *}$ & Rejeitar Ho \\
\hline Q20 & 0,032 & 0,077 & $-1,007$ & Não rejeitar HO & 0,484 & 0,256 & $2,276^{* *}$ & Rejeitar Ho \\
\hline Q21 & 0,419 & 0,333 & 0,865 & Não rejeitar Ho & 0,419 & 0,333 & 0,865 & Não rejeitar HO \\
\hline Q22 & 0,016 & 0,077 & $-1,525$ & Não rejeitar Ho & 0,516 & 0,282 & $2,316^{* *}$ & Rejeitar Ho \\
\hline Q23 & 0,048 & 0,128 & $-1,446$ & Não rejeitar Ho & 0,565 & 0,308 & $2,519^{* *}$ & Rejeitar Ho \\
\hline Q24 & 0,194 & 0,179 & 0,176 & Não rejeitar Ho & 0,532 & 0,385 & 1,447 & Não rejeitar Ho \\
\hline Q25 & 0,226 & 0,154 & 0,884 & Não rejeitar Ho & 0,403 & 0,385 & 0,186 & Não rejeitar HO \\
\hline Q26 & 0,032 & 0,051 & $-0,477^{* * *}$ & Rejeitar Ho & 0,468 & 0,410 & $0,566^{* * *}$ & Rejeitar Ho \\
\hline
\end{tabular}

Enquanto a diferença da proporção de erros dos alunos que cursaram ou não a disciplina foi, estatisticamente, insignificante (sig. < 0,10) na maioria das questões, com exceção das questões Q12, Q16, Q19 e Q26; a diferença da proporção dos alunos que afirmaram não saber responder foi, estatisticamente, significante (sig. < 0,05) em quase todas as questões, com exceção das questões Q10, Q21, Q24 e Q25.

A proporção dos alunos da quarta fase, ou seja, que cursaram a disciplina, que responderam "Não sei" foi menor que dos alunos que não cursaram a disciplina, em todas as questões, e essas diferenças de proporção foram, estatisticamente, significativas, de modo geral. Por outro lado, a proporção de respostas erradas dos alunos que cursaram a disciplina foi maior que dos alunos que não cursaram, em todas as questões, com exceção das questões Q21 e Q24, mas essas diferenças não foram, estatisticamente, significantes, de modo geral.

Por fim, testou-se se o desempenho dos estudantes foi diferente, segundo outras características captadas pelos questionários. O primeiro teste buscou verificar se houve diferença do desempenho entre os alunos que exerciam atividade remunerada ou não. Inicialmente, procedeu-se ao teste de normalidade univariada Shapiro-Francia, cujos resultados foram: grupo de estudantes que exerce atividade remunerada $(z=-0,549$, sig. $=0,708)$ e grupo de estudantes que não exerce atividade remunerada $(z=0,204$, sig. $=$ 0,581 ), de modo que se aceitou a hipótese de que as amostras tinham distribuição normal. Na sequência, procedeu-se ao teste de Levene de igualdade de variâncias, cujo resultado $(F=4,56$, sig. $=0,35)$ indicou que as variâncias não eram homogêneas. Posteriormente, realizou-se o teste $t$ de diferenças de médias, cujo resultado $(t=-1,242$, sig. $=0,217)$ indicou 
não haver diferença entre a média das notas do grupo de estudantes que exerce atividade remunerada, e a média das notas do grupo de alunos que não exerce atividade remunerada.

Também foi investigado se o desempenho dos estudantes que afirmavam conhecer - CEPC diferia do desempenho dos estudantes que afirmavam desconhecê-lo. Da mesma forma, procedeu-se a um teste Shapiro-Francia de normalidade das distribuições das notas dos grupos de alunos que conheciam o $\operatorname{CEPC}(z=1,155$, sig. $=0,123)$ do grupo de alunos que desconheciam o CEPC ( $z=-1,928$, sig. 0,973), indicando que as distribuições eram normais. Na sequência, procedeu-se ao teste de Levene de igualdade de variâncias, cujo resultado $(F=2,876$, sig. $=0,93)$ indicou que as variâncias eram homogêneas. Por fim, procedeu-se ao teste $t$ de diferença de médias, cujos resultados $(t=2,155$, sig. $=0,034)$ indicaram que a diferença de média de notas dos alunos que afirmavam conhecer o CEPC (média 4,35), foi, estatisticamente, diferente das notas dos alunos que afirmavam desconhecer o CEPC (média 3,07 ). Como esperado, os alunos que afirmavam conhecer o CEPC obtiveram desempenho, matemática e estatisticamente, superior aos demais, que afirmavam desconhecer o Instituto.

Por fim, há que se registrar que não foi possível testar a diferença do desempenho dos estudantes segundo a atribuição de importância de existência do CEPC, e segundo a atribuição de importância da existência de Códigos de Ética para Advogados, Administradores e Economistas, informações obtidas com as questões Q7 e Q8 do questionário. Essa impossibilidade ocorreu porque os grupos que concordavam com a importância da existência do CEPC e de Código de Ética para as outras profissões tinham tamanho de $n=99$ (e os que discordavam da importância da existência do CEPC tinham $n=2$ ) e $n=98$ (e os que discordavam da importância da existência de Código de Ética para as demais profissões tinham $n=3$ ), em uma amostra de 101 respondentes, fato que desbalanceava completamente os grupos de teste.

A maciça atribuição de importância da existência do CEPC é corroborada pelas pesquisas de Diehl et al. (2011), Ferreira e Souza (2014), Nascimento et al. (2010), Nunes et al. (2010) e Silva et al. (2010).

\section{CONSIDERAÇÕES FINAIS}

Na área de atuação profissional, seja qual for o ramo, faz-se cada dia mais necessária a presença de pessoas abastadas de atitudes éticas, cobradas por uma sociedade ou grupos sociais que julgam, de acordo com normas, a real conduta a ser seguida.

No ramo da Contabilidade não é diferente. O Contador é testado, diariamente, nos vários âmbitos de sua profissão, sobre os seus valores éticos, pois se encontra puramente envolvido com informações de terceiros e confidenciais. 
Para amparar a profissão do Contador, existe o Código de Ética Profissional do Contador (CEPC) e, diante de sua importância para o desempenho do exercício profissional, pode-se chegar ao objetivo desta pesquisa, que foi medir o conhecimento dos estudantes de Ciências Contábeis acerca do CEPC.

Conforme os dados coletados e analisados, concluiu-se que o conhecimento dos estudantes de Ciências Contábeis da Universidade Federal de Santa Catarina sobre o CEPC é considerado insuficiente no geral, pois apenas $23,8 \%$ deles alcançaram a média de acertos desejável. Porém, se a amostra dos estudantes for avaliada separadamente, por fase, o desempenho se altera.

Percebeu-se que os alunos da quarta fase se saíram melhor do que os da segunda fase, pois a maioria dos estudantes já exerce atividade em Contabilidade e cursou a disciplina de Ética e Filosofia Política (FIL5109). Evidencia-se que ter cursado a disciplina, de alguma forma, contribuiu para o resultado dos estudantes da quarta fase, com o exercício profissional, que agrega o conhecimento teórico com o prático.

Contudo, constatou-se que o número de questões respondidas com "Não Sei" chegou a $56,5 \%$, concluindo que os estudantes não tiveram uma posição sobre a questão.

Ao se analisarem as questões de acordo com os assuntos abordados, as que tiveram melhor colocação foram as relacionadas aos deveres, e as piores foram sobre as penalidades aplicadas aos profissionais. Em seguida, quando se verificou a colocação no geral, por questão, as duas primeiras colocadas foram as que discorreram sobre as proibições ao profissional, e a última colocada a que abordou sobre as penalidades sofridas pelo profissional.

Concluiu-se, ainda, que as questões que não exigiam conhecimento técnico sobre o CEPC e que poderiam ser respondidas com um conhecimento ético, de vivência acadêmica, social e profissional foram as que tiveram maiores acertos, enquanto as que exigiam saber o que, especificamente, consta no CEPC obtiveram os piores índices.

Desse modo, constatou-se, como reflexo dessas análises, o fato de apenas $14 \%$ dos estudantes conhecerem a existência do CEPC, mesmo que em sua grande maioria quase 100\% tenham respondido que acham importante a existência do CEPC. Esses fatos devem ser revistos pela coordenação do Curso e seu corpo docente.

A inserção do CEPC como tópico componente da ementa da disciplina de Ética em Contabilidade e outras denominações similares devem beneficiar os estudantes $e$ o curso, aumentando as notas dos alunos no Exame de Suficiência do Conselho Federal de Contabilidade e no Exame Nacional de Desempenho de Estudantes.

Como os alunos serão os futuros profissionais contadores, a inclusão do CEPC no Plano de Ensino do Curso é de extrema relevância para a área profissional, podendo ajudar a reduzir atitudes antiéticas. 
Como limitação da pesquisa, acrescenta-se que não foram incluídas questões sociodemográficas no questionário, inclusão que pode ser explorada em pesquisas futuras. Também se pode explorar o desempenho dos estudantes em outros exames, como o Exame Nacional de Desempenho dos Estudantes (Enade), bem como realizar a pesquisa com alunos do final do Curso, pois estes, geralmente, possuem maior experiência profissional, e isso pode afetar o conhecimento sobre o Código de Ética. O papel da instituição de ensino, o papel dos conselhos regionais de Contabilidade e mesmo a baixa presença de questões sobre ética nos exames podem ser objetivos de pesquisas futuras, no que se refere ao conhecimento dos estudantes de Ciências Contábeis acerca do Código de Ética.

Sugere-se, ainda, como pesquisa futura, uma análise do conhecimento dos alunos à luz da ementa da disciplina, e uma nova coleta de dados, tendo em vista que, após a coleta de dados da presente pesquisa, a disciplina, que era oferecida na terceira fase do Curso, foi antecipada para a primeira fase.

\section{REFERÊNCIAS}

Almeida, S. R. V., \& Alves, F. J. S. (2015). Testando o Triângulo de Cressey no contexto da convergência às normas internacionais de contabilidade: Um estudo empírico sobre comportamento ético de profissionais de contabilidade. Revista de Administração da UFSM, $8(2), 282-297$.

Brancher, C., Neu, M. A., \& Boff, M. L. (2010). Ética profissional: Entendimento dos acadêmicos de Ciências Contábeis da Unoesc. Unoesc \& Ciência-ACSA, 1(1), 31-38.

Bueno, C. V. (2017). Desenvolvimento das pesquisas sobre ética profissional contábil no Brasil e no exterior: Um estudo bibliométrico de 2010 a 2013. Revista Livre de Sustentabilidade e Empreendedorismo, 2(2), 4-27.

Camargo, M. (2009). Fundamentos de ética geral e profissional ( $8^{a}$ ed.). Petrópolis: Vozes.

Campos, S. A. S. P., \& Lima, M. (2013, outubro). Ética na Profissão Contábil: Um estudo sobre a percepção dos alunos sobre a contribuição da disciplina "Ética e legislação profissional" para a formação em Ciências Contábeis. Anais do Encontro de Produção Científica e Tecnológica, Campo Mourão, 8, 1-15.

Chen, C., Gotti, G., Kang, T., \& Wolfe, M. C. (2018). Corporate Codes of Ethics, National Culture, and Earnings Discretion: International Evidence. Journal of Business Ethics, 151(1), 141-163.

Conselho Federal de Contabilidade. (1996). Resolução CFC 803. Aprova o Código de Ética Profissional do Contador-CEPC. Brasília, DF: CFC. 
Conselho Federal de Contabilidade. (2011). Exame de Suficiência. Bacharel em Ciências Contábeis ( $1^{a}$ ed.). Brasília, DF: CFC. Recuperado de https://cfc.org.br/wp-content/uploads/2016/02/BACHAREL_I_2011.pdf

Cooper, D. R., \& Schindler, P. S. (2016). Métodos de pesquisa em administração (12a ed.). Porto Alegre: AMGH.

Cressey, D. R., \& Moore, C. A. (1983). Managerial values and corporate codes of ethics. California Management Review, 25(4), 53-77.

Diehl, C. A., Freitas, A. C., \& Macagnan, C. B. (2011). A percepção sobre ética de estudantes de curso de graduação em Ciências Contábeis. Revista de Educação e Pesquisa em Contabilidade, 5(1), 21-49.

Feil, A. A., Diehl, L., \& Schuck, R. J. (2017). Ética profissional e estudantes de contabilidade: Análise das variáveis intervenientes. Cadernos EBAPE.BR, 15(2), 256-273.

Ferreira, P. C., \& Souza, M. A. (2014). Ética: Percepção sobre a ética dos alunos iniciantes e concluintes do curso de Ciências Contábeis do UNIBH. Convibra, 11.

Gil, A. C. S. (2016). Presença do tema ética nos projetos político/pedagógicos dos cursos da FACE/UFG (Trabalho de conclusão de curso). Recuperado de http://repositorio.bc.ufg.br

Lima, M. E. B., Prazeres, R. V. D., Araújo, J. G. N. D., \& Araújo, J. G. D. (2014). Ética em Contabilidade: Um estudo sobre a percepção dos discentes acerca da ética profissional. Revista de Gestão e Contabilidade da UFPI, 1(2), 121-134.

Lisboa, L. P. (2010). Ética geral e profissional em contabilidade (2a ed.). São Paulo: Atlas.

Liu, X. (2016). Corruption culture and corporate misconduct. Journal of Financial Economics, $122(2), 307-327$.

Mafra, E. J. S., Teixeira, A. A. S., Silva, L. S., Costa, L. M., \& Costa, P. S. (2007). Análise do nível de conhecimento dos graduandos sobre o código de ética do contabilista: $O$ caso dos alunos do Curso de Ciências Contábeis da Universidade Federal de Uberlândia. Anais do Congresso UFSC de Iniciação Científica em Contabilidade, Florianópolis, 1.

Malhotra, N. (2019). Pesquisa de Marketing: Uma Orientação Aplicada (7a ed.). Porto Alegre: Bookman. 
Marçal, R. R., Matos, V. da S., Carvalho, T. F. M. de, \& Carvalho, M. da S. (2019). Avaliações de desempenho no ensino contábil brasileiro: Uma análise comparativa entre IES diante do Exame de Suficiência do CFC. RACE, Revista de Administração, Contabilidade e Economia, 18(2), 363-384.

Medeiros, A. W., \& Vieira, E. R. F. C. (2010). Percepção comparativa no âmbito da ética entre os alunos do Curso de Ciências Contábeis do $1^{\circ}$ e $4^{\circ}$ ano da FARN. Interface-Revista do Centro de Ciências Sociais Aplicadas, 7(1), 93-108.

Merchant, K. A., \& White, L. F. (2017). Linking the Ethics and Management Control Literatures. Advances in Management Accounting, 28(1), 1-29.

Monteiro, J. E. R., Silva, G. I. S, Peter, M. G. A., \& Machado, M. V. V. (2011, outubro). Ética e Contabilidade: Estudo bibliométrico das publicações dos anais do Enanpad na primeira década do século XXI. Anais do Seminários em Administração-SemeAd, São Paulo, SP, 14.

Moraes, M. C. C., Silva, A. M. C., \& Carvalho, F. A. A. (2010). O comportamento dos futuros contabilistas perante diferentes dilemas éticos. Pensar Contábil, 12(48), 22-30.

Nascimento, C., Bezerra, T. L., Espejo, M. M. D. S. B., Pacheco, V., \& Antonovz, T. (2010). O tema "ética" na percepção dos alunos de Graduação de Ciências Contábeis em universidades da região Sul do Brasil. Revista Contemporânea de Contabilidade, 7(14), 75-96.

Neu, D., Everett, J., \& Rahaman, A. S. (2015). Preventing corruption within government procurement: Constructing the disciplined and ethical subject. Critical Perspectives on Accounting, 28, 49-61.

Nunes, R. R. B., Leite, T. R. T., \& Souza, E. X. (2010, setembro). Ética contábil: A percepção dos alunos do Curso de Ciências Contábeis da Universidade Federal de Alagoas. Anais dos Seminários em Administração-SemeAd, São Paulo, SP, 13.

Oliveira, R. R., Jesus, V. P. M., Silva, E. V., Silva, U. E., \& Nascimento, V. M. S. (2014, outubro). Percepção dos alunos de Ciências Contábeis de uma instituição de ensino superior do Rio de Janeiro sobre a disciplina Ética. Anais do Simpósio de Excelência em Gestão e Tecnologia, Resende, 11.

Rocha, L. F., Oliveira, E. P. S., Borges, S. S., \& Sanchez, A. F. C. (2015, outubro). A percepção da ética por parte dos discentes de graduação que atuam na área contábil. Anais do Congresso Nacional de Administração e Contabilidade, Rio de Janeiro, RJ, 6.

Sá, A. L. (2010). Ética profissional (9ª ed.). São Paulo: Atlas. 
Sampieri, R. H., Collado, C. F., \& Lucio, M. P. B. (2013). Metodologia de pesquisa (5a ed.). Porto Alegre: Penso.

Silva, K. A. (2014). Percepção a respeito da ética na profissão contábil: Um estudo com os concluintes do Curso de Ciências Contábeis da Universidade Estadual da ParaíbaUEPB (Trabalho de conclusão de curso). Recuperado de http://dspace.bc.uepb.edu.br/

Silva, W. A. C., Oliveira, M. C. S. M., Ramos, M. A., \& Soares, S. F. (2010, novembro). A Importância e o Conhecimento sobre Ética: $O$ olhar de discentes do Curso de Ciências Contábeis. Anais do Congresso Brasileiro de Custos, Belo Horizonte, 17.

Soltani, B. (2014). The anatomy of corporate fraud: A comparative analysis of high profile American and European corporate scandals. Journal of business ethics, 120(2), 251-274.

Timmons, J. F., \& Garfias, F. (2015). Revealed corruption, taxation, and fiscal accountability: Evidence from Brazil. World Development, 70, 13-27.

Trentin, G. N. S., Domingues, M. J. C. S., \& Castro, D. R. M. S. (2008, novembro). Percepção dos alunos de Ciências Contábeis sobre ética profissional. Anais do Congresso Brasileiro de Custos, Curitiba, PR, 15.

\section{Como citar este artigo:}

\section{ABNT}

CUNHA, Karina Silveira da et al. O conhecimento dos estudantes de Ciências Contábeis acerca do Código de Ética. RACE, Revista de Administração, Contabilidade e Economia, Joaçaba: Editora Unoesc, v. 19, n. 3, p. 489-512, set./dez. 2020. Disponível em: http:// editora.unoesc.edu.br/index.php/race. Acesso em: dia/mês/ano.

\section{APA}

Cunha, K. S. da, Casagrande, M. D. H., Soares, S. V., \& Góis, A. D. (2020). O conhecimento dos estudantes de Ciências Contábeis acerca do Código de Ética. RACE, Revista de Administração, Contabilidade e Economia, 19(3), 489-512. Recuperado de http://editora. unoesc.edu.br/index.php/race 
